\title{
Screening of benzofuran compound 3-acetamido-2-p-anisoyl benzofuran for anti-inflammatory activity in acute models of inflammation
}

\author{
Lakshminarayana K.*, Umesh G. Wari, Suresh S. Kendri
}

Department of Pharmacology, Vijayanagar Institute of Medical Sciences, Ballari, Karnataka, India

Received: 22 January 2016

Accepted: 04 February 2016

\section{*Correspondence to:}

Dr. Lakshminarayana K., Email: blydrkln@gmail.com

Copyright: (C) the author(s), publisher and licensee Medip Academy. This is an openaccess article distributed under the terms of the Creative Commons Attribution NonCommercial License, which permits unrestricted noncommercial use, distribution, and reproduction in any medium, provided the original work is properly cited.

\begin{abstract}
Background: Benzofurans are colourless solid compounds which are derived from coal tar. They have been shown to have many properties which are relevant to the field of pharmacology. For example they have significant antibacterial, antifungal, antidepressant and anti-arrhythmic properties. In some of the studies carried out on them they have shown to have anti-inflammatory activity also. So this study was conducted to know if the compound 3acetamido-2-p-anisoyl benzofuran has anti-inflammatory activity in acute inflammation.

Methods: The benzofuran compound understudy and phenylbutazone were administered orally to wistar albino rats in the dose of $100 \mathrm{mg} / \mathrm{kg}$ body weight, with $2 \%$ gum acacia as suspending agent and the effects were observed in acute models of inflammation viz, carrageenin induced rat paw edema, and turpentine induced peritonitis.

Results: The results of our study showed that the benzofuran compound under study has significant anti-inflammatory activity in both the experimental models of acute inflammation.

Conclusions: Results from our study show that the compound under study has significant anti-inflammatory activity and further detailed works with this compound in different doses are needed.
\end{abstract}

Keywords: Acute inflammation, Benzofurans, Carrageenin, Phenylbutazone, Turpentine, Peritonitis

\section{INTRODUCTION}

Benzofurans are colourless solid compounds derived from coal tar. Chemically they are heterocyclic compounds containing fused benzene and furan rings. Benzofuran derivatives have broad spectrum pharmacological activities like antibacterial, antifungal, antidepressant, and antiarrhythmic and anti-inflammatory properties. $^{1-5}$

Inflammation is a defensive response of body against the harmful stimuli. This is intended to remove the injury causing stimuli and initiate the process of repair.

This inflammation can be elicited by various stimuli like physical injury, heat, antigen-antibody reaction, infection and ischemia. Macroscopically inflammation is associated with clinical signs like erythema, edema, tenderness and pain. Inflammation basically consist of 3 phases, namely (1) An acute transient phase characterized by vasodilation, increased capillary permeability (2) A delayed sub-acute phase involving infiltration of leucocytes and phagocytic cells (3) A chronic proliferative phase consisting of tissue degeneration and fibrosis. ${ }^{6}$

A number of natural substances like prostaglandins, histamine and serotonin have been shown to be the mediators of inflammation. Prostaglandins are synthesised from arachodonic acid via cyclooxygenase pathway mediated by cyclooxygenase enzyme. 7 So benzofurans being inhibitors of cyclooxygenase enzyme can be of use in preventing noxious effects of inflammatory response. ${ }^{8}$

Hence based on the afore mentioned concepts we took up this study to assess if the benzofuran compound "3- 
acetamido-2-p-anisoyl benzofuran" has antiinflammatory activity in acute models of inflammation.

\section{METHODS}

Benzofuran compound "3-acetamido-2-p-anisoyl benzofuran" was the test drug used for this particular study. It is a white solid, insoluble in water. It has the following structural formula.

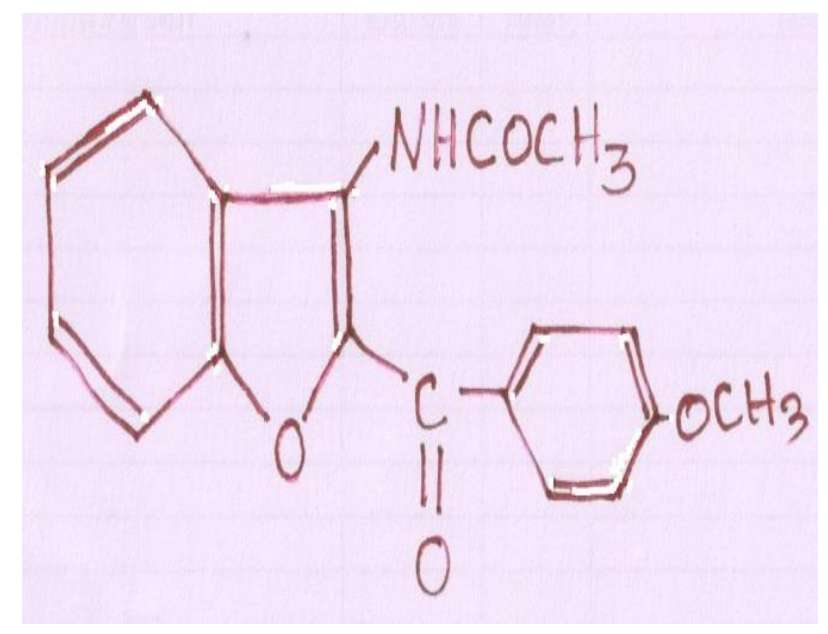

Figure 1: 3-acetamido-2-p-anisoyl benzofuran.

The benzofuran compound used for this study was synthesised by Dr. Y. Agasimundin, reader in Chemistry, Gulbarga University, Gulbarga.

A pyrazolone derivative, phenylbutazone with chemical formula, 3, 5-dioxo-1, 2-diphenyl-4-n-butyl pyrazolidine, a well known anti-inflammatory drug was used as the standard drug in our study. ${ }^{9}$ It was obtained from pacific pharmaceuticals Pvt. Ltd., Bengaluru.

Both the above mentioned drugs were administered orally as suspension with $2 \%$ gum acacia, in the dose of 100 $\mathrm{mg} / \mathrm{kg}$ body weight with the help of polythene tube. An equal volume of plain $2 \%$ gum acacia acted as control drug.

Animals used in our study were wistar albino rats of either sex of average weight 120 to $200 \mathrm{~g}$ these rats were inbred in the central animal house of VIMS, Ballari. The study was done after getting the clearance of Institutional animal ethical committee.

All the animals were allowed food and water ad libitum both being withdrawn just prior to the experiment. The animals were housed in a polypropylene cage under standard conditions in dim light and noise free room.

The models used for inducing acute inflammation in rats were carrageenin induced rat paw edema, and turpentine induced peritonitis.
The rats were divided into two major groups, one for the carrageenin induced inflammation and another group for the turpentine induced peritonitis.

Carrageenin induced rat paw edema model: The first group of rats to be used in this model were sub divided into three groups of six rats each, one group of rats acting as control were treated with $2 \%$ gum acacia orally, and another group received standard drug phenylbutazone in the dose of $100 \mathrm{mg} \mathrm{kg}$ body weights orally and the remaining group was treated with test compound benzofuran in the dose of $100 \mathrm{mg} \mathrm{kg}$ body weight orally.

All the drugs were administered $1 \mathrm{~h}$ prior to the sub plantar injection of inflammation inducing agent carrageenin in $0.05 \mathrm{ml}$ in the right hind paw.

The right hind paw volume was measured by using mercury plethysmograph, immediately after the sub plantar injection of carrageenin, ( $0 \mathrm{~h}$ volume $)$ and at the end of 4 hours. The difference between the $0 \mathrm{~h}$ paw edema volume and volume measured after 4 hours indicated the actual edema.

The mean paw edema volume of animals in both the groups were taken and the anti-inflammatory activity of drugs was measured by the formula,

Percent of inhibition of edema i.e. anti-inflammatory activity $=100\left[1-\mathrm{V}_{\mathrm{t}} \mid \mathrm{V}_{\mathrm{c}}\right]$

Where $V_{t}$ is the mean volume of paw edema in drug treated group, and $\mathrm{V}_{\mathrm{c}}$ is the mean volume of paw edema in the control group.

Turpentine induced peritonitis model: In this model the rats were divided into three groups of six each. Here again $2 \%$ gum acacia acted as control and $100 \mathrm{mg} / \mathrm{kg}$ of phenylburazone as standard drug and benzofuran in the dose of $100 \mathrm{mg} / \mathrm{kg}$ body weight acted as test drug. Peritonitis was induced by intraperitoneal injection of 0.5 $\mathrm{ml}$ of turpentine. All the drugs were given orally with gum acacia as a suspending agent, 1 hour prior to intra peritoneal injection of $0.5 \mathrm{ml}$ of turpentine. After the end of 4 hour, the animals were sacrificed and the exudates were collected and measured immediately by cutting open the abdomen. The same formula was used as in the carrageenin model to calculate the percent of antiinflammatory activity.

\section{Statistical analysis}

All the data obtained were tabled as mean and standard error for mean; the data were analysed using students ttest. 


\section{RESULTS}

\section{Carrageenin induced rat paw edema model}

In this model there was a significant reduction in the amount of rat paw edema volume in Benzofuran compound as compared to control group. i.e., the understudy Benzofuran compound showed significant anti-inflammatory activity with $\mathrm{p}$ value being $\mathrm{p}<0.05$.

Table 1 shows that the understudy benzofuran compound has got significant anti-inflammatory activity, the significant values being shown with asterisks. The same being illustrated in Figure 2.

Table 1: Carrageenin induced rat paw edema model.

\begin{tabular}{|ll|l|}
\hline Groups & $\begin{array}{l}\text { Mean paw edema } \\
\text { volume }(\mathbf{c m}) \pm \text { SEM }\end{array}$ & $\begin{array}{l}\text { Percent } \\
\text { inhibition }\end{array}$ \\
\hline Control & $0.61 \pm 0.030$ & ------ \\
\hline $\begin{array}{l}\text { Phenylbutazone } \\
\text { (standard) }\end{array}$ & $0.25 \pm 0.028$ & $59.02^{*}$ \\
\hline $\begin{array}{l}\text { Benzofuran (test } \\
\text { drug) }\end{array}$ & $0.35 \pm 0.04$ & $42.63^{*}$ \\
\hline
\end{tabular}

*indicates significant $\mathrm{p}$ value $\mathrm{p}<0.05$

$\mathrm{SEM}$ - Standard error of the mean

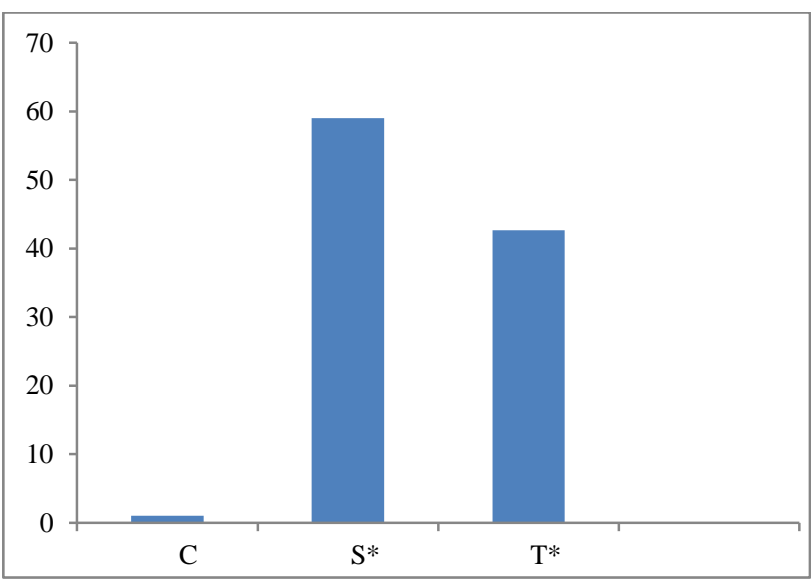

$\mathrm{Y}$ axis indicates the percent of inhibition; $\mathrm{C}-\mathrm{Control}(2 \%$ gum acacia); S - Standard drug (Phenylbutazone); T - Test drug; (Benzofuran compound); *indicates significant $p$ value $p<0.05$.

\section{Figure 2: The percent of inhibition in carrageenin induced rat paw edema model.}

\section{Turpentine induced peritonitis}

The amount of exudation that was formed in benzofuran compound group was significantly lower than the control group i.e., in this model also the test compound showed significant anti-inflammatory activity.

Table 2 shows that the test compound i.e., the benzofuran has got significant anti-inflammatory activity, the same being depicted in bar chart form in Figure 3.
Table 2: Turpentine induced peritonitis model.

\begin{tabular}{|ll|l|}
\hline Groups & $\begin{array}{l}\text { Mean peritoneal } \\
\text { exudates volume } \\
(\mathrm{ml}) \pm \text { SEM }\end{array}$ & $\begin{array}{l}\text { Percent } \\
\text { inhibition }\end{array}$ \\
\hline Control & $3.52 \pm 0.21$ & ------- \\
\hline $\begin{array}{l}\text { Phenylbutazone } \\
\text { (standard) }\end{array}$ & $1.91 \pm 0.14$ & $45.74^{*}$ \\
\hline $\begin{array}{l}\text { Benzofuran (test } \\
\text { drug) }\end{array}$ & $2.22 \pm 0.17$ & $36.94^{*}$ \\
\hline
\end{tabular}

*indicates significant $\mathrm{p}$ value $\mathrm{p}<0.05$; SEM - Standard error of the mean.

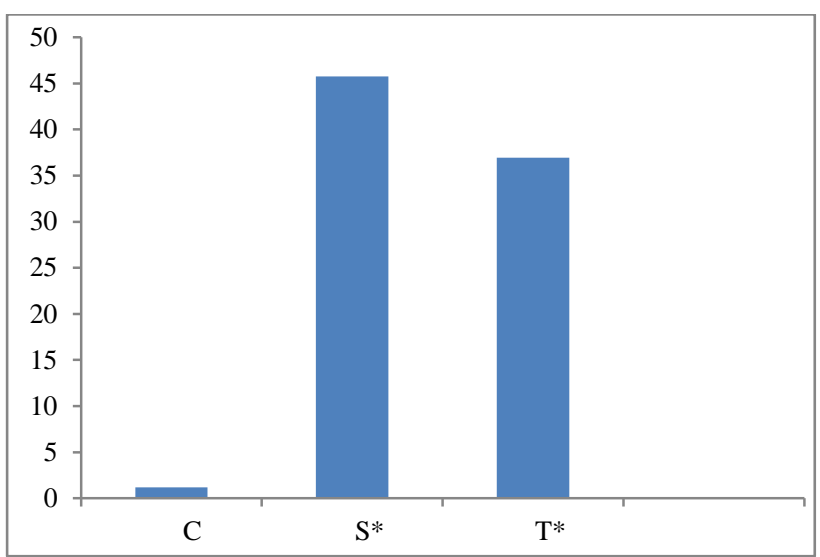

$\mathrm{Y}$ axis indicates the percent of inhibition; $\mathrm{C}$ : Control (2\% gum acacia); S: Standard (Phenylbutazone); T: Test drug (Benzofuran compound); *indicates the significant $\mathrm{p}$ value $\mathrm{p}$ $<0.05$.

\section{Figure 3: Percent of inhibition in turpentine induced peritonitis model.}

\section{DISCUSSION}

Inflammation is the local reaction of vascularised tissue to injury. Acute inflammation is early and immediate stereotypical response which is common to all forms of injury, irrespective of the causative agent. It is of short duration, lasting from few minutes to several hours or sometimes upto 1-2 days. It is mainly characterized by exudation of fluid and plasma protein and emigration of leucocytes, and release of chemotactic factors. All these processes involved in acute inflammation are mediated by prostaglandins, leukotrienes histamine and serotonin and many more endogenous substances whose list is ever increasing because of ongoing research work over inflammation. Even today the mystery of inflammation is still to be explored as the causes for inflammation are dwindling in nature leading to so many diseases of weired aetiology causing a kind of array in choosing the drugs to treat these conditions, though there are humpty number of innumerable anti-inflammatory agents are available in the market, the saga for continuing to explore newer and newer drugs for these kinds of ailments continues and the destiny is yet to be explored.

In this context our attempt is made to find an insight in to the promised anti-inflammatory activity of this 
Benzofuran compound, "3-acetamido-2-p-anisoyl benzofuran", is earnestly made in this study. The present study indicates that the benzofuran compound have exhibited nearly 36\%, $42 \%$ anti-inflammatory activity which may not sound as a solid anti-inflammatory agent, however with structural modifications we may arrive at an ideal anti-inflammatory agent in due course of time.

In the present study conducted by us, it was observed that the understudy benzofuran compound showed significant anti-inflammatory activity in both the models of inflammation. These observations can be accounted for by the fact that the benzofuran compounds and their derivatives are potent inhibitors of enzymes like cyclooxygenases and lipoxygenases. ${ }^{8}$ These enzymes as mentioned above are responsible for the synthesis of prostaglandins from the membrane phosholipid arachidonic acid. So these benzofurans by inhibiting the synthesis of one of the main mediators of inflammation, viz., prostaglandins mitigate the effects of inflammation.

\section{CONCLUSION}

With our study we conclude that the benzofuran compound has got significant anti-inflammatory activity. It may become one of the better NSAID's of the near future which may not be very far away from it. If its antiinflammatory activities are further explored in human trials with different dosage profiles and with structural modifications we may fathom out the ideal and reliable less toxic, gut friendly with less burden on the excretory system like renal system may bloom with all these pinnacle criteria.

Funding: No funding sources Conflict of interest: None declared

Ethical approval: The study was approved by the Institutional Ethics Committee

\section{REFERENCES}

1. Kirilmis C, Ahmedzade M, Servi S, Koca M, Kizirgil A, Kazaz C. Synthesis and antimicrobial activity of some novel derivatives of benzofuran: part 2. The synthesis and antimicrobial activity of some novel 1-(-1-benzofuran-2-yl)-2mesitylethanone derivatives. Eur J Med Chem. 2008;43(2):300-8.

2. Shazia NA, Philip CS, Daniel RH. Synthesis of cicerofuron an antifungal benzofuran and some related analogues. Tetrahedron. 2006;62:4214-26.

3. Malik WU, Mahesh VK, Raishgani M. Synthesis and biological evaluation of some benzofuran derivatives. Indian J Chem. 1971;9:655.

4. Bourgery G, Dostert P, Lacour A, Langlois M, Pourrias B, Tisne-Versailles J. Synthesis and antiarrhythmic activity of new benzofuran derivatives. J Med Chem. 1981;24(2):159-67.

5. Balasaheb JM, Agasimundin YS. Microwave assisted synthesis of benzofuran analogues of fenamates as NSAIDS. J Child Chem Soc. 2009;54(1):77-9.

6. Mitchell RN, Cotran RS. In: Robbins Basic Pathology $7^{\text {th }}$ Edition. Philadelphia: Elsevier-Health Publications. 2002:33.

7. Tripathi KD. In: Essentials of Medical Pharmacology. 7 th Edition. New Delhi: Jaypee Brothers Medical Publishers. 2013:193.

8. Chakrabarti JK, Eggeleton RJ, Gallagher PT, Harvey J, Hicks TA, Kitchen EA. 5-Acyl -3substituted - benzofuran $-2(3 \mathrm{H})$ - ones as potential anti-inflammatory agents. J Med Chem. 1987;30(9):1663-8.

9. Wagner W, Khanna P. In: Katzungs Basic and Clinical Pharmacology. $9^{\text {th }}$ edition. New York: McGraw Hill. 2001:586.

Cite this article as: Lakshminarayana $\mathrm{K}$, Wari UG, Kendri SS. Screening of benzofuran compound 3acetamido-2-p-anisoyl benzofuran for anti-inflammatory activity in acute models of inflammation. Int J Basic Clin Pharmacol 2016;5:239-42. 